\title{
Success of collaboration for sustainable agriculture: a case study meta-analysis
}

\author{
Sarah Velten ${ }^{1} \cdot$ Nicolas W. Jager ${ }^{2} \cdot$ Jens Newig ${ }^{1}$
}

Received: 11 September 2019 / Accepted: 20 January 2021 / Published online: 5 February 2021

(c) The Author(s) 2021

\begin{abstract}
More and better collaboration between farmers and other stakeholders has repeatedly been identified as a key strategy for sustainable agriculture. However, for collaboration to actually benefit sustainable agriculture certain conditions have to be met. In this paper, we scrutinize the conditions that support or hamper the success of collaborative efforts in the context of sustainable agriculture. For this purpose, we conducted an exploratory case study meta-analysis to consolidate insights from 30 case studies on local and regional collaborative groups for a more sustainable agriculture in the EU. Through multiple regression analysis, we evaluated which factors influence the 'success' of such collaboratives. Thereby, we measured success through five explicit and comprehensive success criteria. We found two external, five actor-related, and five organization and management-related factors to decisively influence the different success criteria. Overall, our results highlight that collaboration success requires defining priorities as for each of the success criteria a different set of factors is decisive. Although our results showed trade-offs between the achievement of social and economic goals, it is possible to pursue some success criteria simultaneously. Furthermore, our results give reason to be optimistic about the performance of collaboratives: internal factors, which are in the hand of the collaboratives, are likely to be of greater importance than uncontrollable external conditions. Additionally, conditions encountered at the outset of a collaborative matter less than the way these conditions develop toward later stages. Thus, rather than depending on external and predefined conditions, success largely depends on the agency within the collaboratives.
\end{abstract}

Keywords Sustainable development · Farming · Collaboratives · European Union · Local · regional $\cdot$ Case survey method $\cdot$ Multiple regression

Sarah Velten

sarah.velten@yahoo.de

Nicolas W. Jager

nicolas.jager@uni-oldenburg.de

Jens Newig

newig@uni.leuphana.de

1 Institute of Sustainability Governance, Leuphana University Lüneburg, Universitätsallee 1, 21335 Lüneburg, Germany

2 Department of Business Administration, Economics and Law, Carl Von Ossietzky Universität Oldenburg, AmmerländerHeerstr. 114-118, 26129 Oldenburg, Germany 


\section{Introduction}

More and better collaboration between farmers and other related actors has repeatedly been identified as a key strategy for sustainable agriculture (Beus and Dunlap 1990; Pretty 1995b; Cobb et al. 1999; Warner 2007; Velten et al. 2015). Collaboration is considered to directly and indirectly contribute to the generation of ecological, social, and economic benefits in agricultural contexts: arguably, collaboration allows for the effective management of natural resources and coordination of farming practices. The reason for this is that it allows acting at scales that are more appropriate to the spatial range of ecological processes than the traditionally targeted field or farm-scales. For instance, if the installation of landscape features is coordinated on a landscape-scale across several farms, habitat connectivity as well as overall landscape complexity can be improved (Donald and Evans 2006; Concepción et al. 2008; Leventon et al. 2017). In the same vein, collaboration can also support the harmonization of multiple objectives. In sum, collaboration may result in a reduction in habitat fragmentation and better connected ecological networks (Uetake 2014; Prager 2015; Leventon et al. 2017). In terms of social outcomes, collaboration is said to increase social interaction and capital beyond the collaborative initiative itself. It thus is supposed to enhance the feeling of belonging within a community as well as the willingness of people to provide advice and mutual support (Ingram et al. 2008; Prager 2015). Furthermore, it has been argued that collaborative groups have greater negotiation power, are able to realize bigger, joint investments (Oerlemans and Assouline 2004), and are more likely to receive funding by donor organizations than individual actors (Ramdwar et al. 2013). Additionally, collaboration supposedly allows for increased efficiency through minimization and sharing of costs (Uetake 2014; Prager 2015; Lamichhane et al. 2016; Fischer et al. 2018). It has also been suggested that collaboration facilitates pooling and sharing of knowledge and capacities (Oerlemans and Assouline 2004; Shaw et al. 2009; Uetake 2014), individual and collective learning (Oerlemans and Assouline 2004; Newig et al. 2019), and more legitimate, flexible, and locally relevant solutions (Uetake 2014; Prager 2015). All of these qualities can further support the generation of social, ecological and economic benefits.

However, collaboration also faces challenges (Uetake 2014; Prager 2015; Lamichhane et al. 2016). Arguably, certain conditions have to be met in order to render collaboration successful. In this paper, we scrutinize the conditions that support or hamper the success of collaborative efforts in the context of sustainable agriculture. In fact, there already exists a noteworthy number of publications that consider conceptually or empirically which conditions affect the success of collaborative initiatives in areas similar to sustainable agriculture. Examples are literature on farmer collaboration for agri-environmental management (Ingram et al. 2008; Prager 2015), collective action (Ayer 1997; Oerlemans and Assouline 2004; Mills et al. 2011) and social networks (Lubell and Fulton 2007; Newman and Dale 2007). However, the existing literature lacks a specific focus on collaboration in the context of sustainable agriculture (exceptions are Shaw et al. 2009; Moschitz et al. 2014; Hubeau et al. 2017) and investigates only small numbers of cases. Although such in-depth case study research of few cases allows deep insights into causal mechanisms, it does not allow for the identification of overall patterns. Also, generalizability of the results remains critical.

Therefore, in this paper we aim at consolidating insights from a larger number of case studies on collaborative initiatives for a more sustainable agriculture in order to evaluate against explicit and comprehensive success criteria which factors influence the success of 
such initiatives. Such factors include both external conditions, which cannot be influenced by a collaborative initiative, as well as aspects of composition, organization, and management of collaborative groups. For this purpose, we conducted an exploratory case-meta analysis, also referred to as case survey (Lucas 1974; Larsson 1993; Newig and Fritsch 2009), on local and regional collaborative initiatives for a more sustainable agriculture in the EU. Our approach is exploratory because the research field is dominated by a considerable amount of small-N case studies and evidence is rather scattered. Thus, there is a need for consolidation of knowledge rather than for hypothesis testing. The central feature of the case study meta-analysis is the quantitative coding of variables for each investigated case study. This approach is especially useful here as it allows for statistical analysis of qualitative case study narratives. This, in turn, allows producing findings of broader relevance beyond a single case study.

The remainder of this paper is organized as follows: the subsequent section introduces the conceptual background of our research. Here, we clarify core concepts of our research and present our analytical framework. Section 3 describes our research methods and case selection. The results of a regression analysis explaining sustainable outcomes by the 'success factors' developed previously are presented and discussed in Sects. 4 and 5. In the final section, we draw conclusions and highlight future research needs.

\section{Conceptual background}

Below, we first describe our understanding of the core concepts: collaboration and sustainable agriculture. Afterwards, we introduce our analytical framework with its dependent variables (success criteria) and independent variables (success factors).

\subsection{Clarification of core concepts}

\subsubsection{Collaboration}

Based on Margerum (2011), we refer to 'collaboration' as an approach to solving complex problems in which a diverse group of autonomous stakeholders makes collective decisions and translates these decisions to tangible results. With that, we only refer to collaboration in the way also Schoon and Cox (2018) use the term ("working together as a collective entity") and do not include what they describe as coordination ("conducting individual actions while informing the "other' about what is being done"). Furthermore, we also adopt Margerum's (2011) term 'collaborative' to describe the groups carrying out collaboration.

\subsubsection{Sustainable agriculture}

With 'sustainable agriculture,' we mean an approach that applies specific strategies in a variety of fields of action in order to achieve sustainability goals in the environmental, economic, and social domains in an integrated way. Strategies for sustainable agriculture can be, for instance, adaptive management, holistic and complex systems thinking, an ecologybased or an economics-based strategy. Such strategies can be applied in diverse fields of action such as the agri-food system, management and technological solutions, or the social, political, and economic environment (Velten et al. 2015). Such a broad view of sustainable agriculture allows us to embrace a great variety of collaboratives that contribute to 
sustainable agriculture. Thus, we address collaboratives ranging from farmer initiatives in search of more sustainable production techniques to agricultural supply chain initiatives with diverse involved actors trying to establish sustainable standards, and to consumer or citizen initiatives seeking ways to support sustainable agriculture.

\subsection{Analytical framework}

In order to gain an understanding of the kinds of factors that potentially influence the success of collaboratives for a more sustainable agriculture, we conducted a literature review. We looked at conceptual and empirical literature investigating conditions for success of collaborative ventures in the context of agriculture and rural development, especially works investigating sustainability issues more comprehensively and publications focusing specifically on environmental issues. The reviewed literature included works on collaborative common-pool resource institutions (e.g., Ostrom 1990; Agrawal 2001), farmer collaboration for agri-environmental management (Ingram et al. 2008; Prager 2015), communitybased natural resource management (Measham and Lumbasi 2013), collective action (e.g., Ayer 1997; Oerlemans and Assouline 2004; Mills et al. 2011), social networks (e.g., Lubell and Fulton 2007; Newman and Dale 2007), advocacy coalitions (Schlager 1995; Sabatier 1988), partnerships (Clark 2006; Dyer et al. 2013), cooperatives (e.g., Carlberg et al. 2003; Azadi et al. 2010), as well as public policy design related to sustainability and land management (e.g., Cocklin et al. 2007; Prager et al. 2011).

Based on the reviewed literature, we developed our analytical framework (Fig. 1): different kinds of external and internal success factors can impact on the overall success of a collaborative by supporting or hampering different success criteria. While there are likely to be many interconnections and feedback loops among and between the different success factors and success criteria, here we are only interested in the effects of the potential success factors on the different success criteria. The following sections explain the different success factors and success criteria.

\subsubsection{Success of collaboratives for a more sustainable agriculture}

In contrast to the great detail on factors influencing the success of collaborative efforts, we found few clear definitions or explanations of how success of a collaborative is understood in the reviewed literature. However, in order to assess the impact of a success factor on the performance of a collaborative, an explicit understanding of the concept of success is necessary. Therefore, by departing from and extending McConnell's (2010) definition of policy success we derived a list of success criteria (see Velten 2014 for more detail):

- Achievement of the social, environmental, and economic goals of a collaborative: Estimation of the extent to which a collaborative was able to realize the objectives it set out to achieve.

- Durability: Estimation of the actual or likely endurance of a collaborative and its achievements despite changing conditions (e.g., ceasing of financial support).

- Acceptance of a collaborative: Estimation of the extent to which a collaborative itself is supported or opposed by the involved and other affected actors; different from the other measures, this measure is not related to (intended or unintended) tangible outcomes but rather to the way the collaborative operated and achieved its outcomes. 


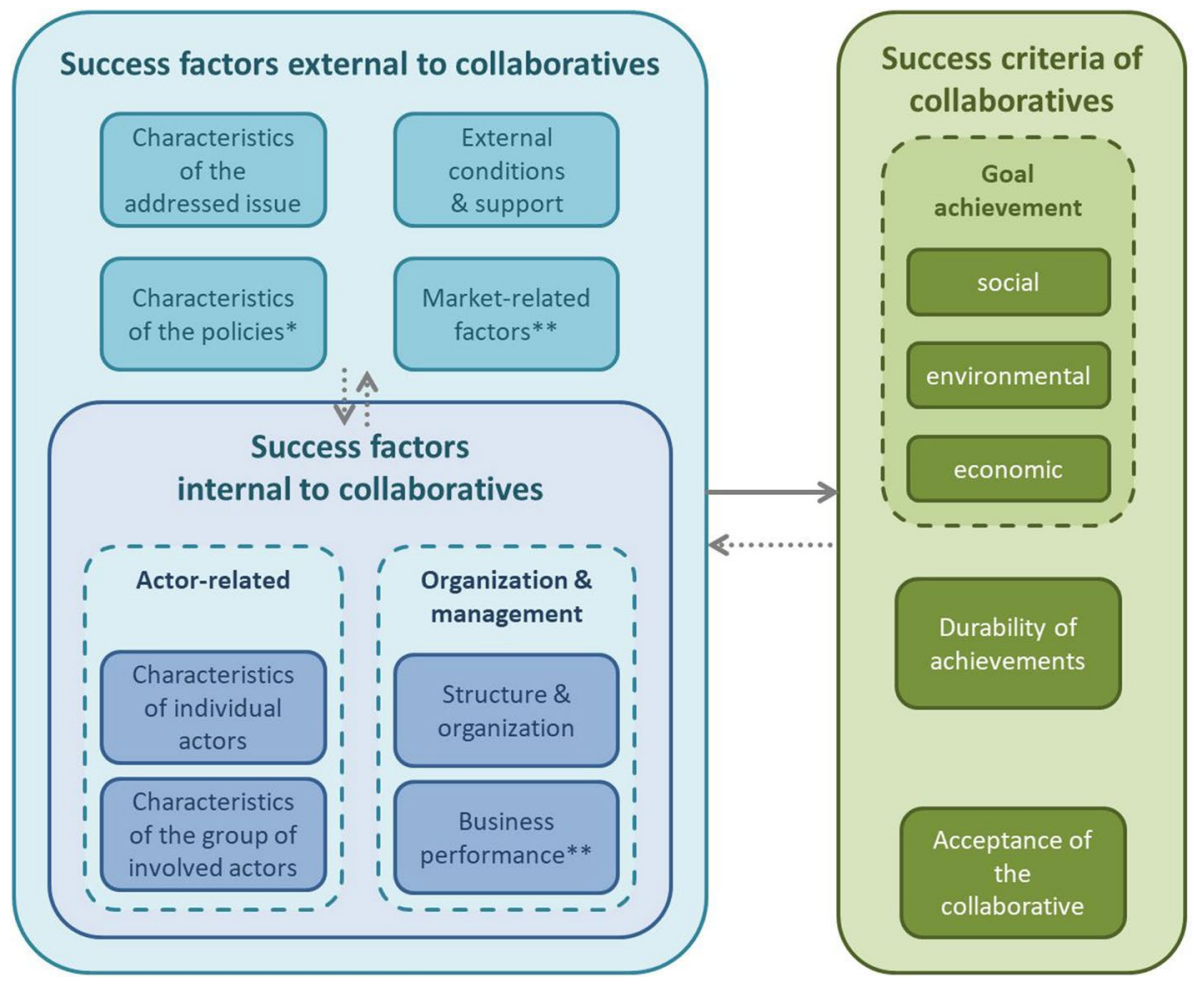

Fig. 1 Conceptual framework including the different kinds of potential success factors identified in the literature (left side) and success criteria (right side). The arrows show potential influence between success factors and success criteria as well as between external and internal success factors: the continuous arrow shows the relation of interest to the research presented here; the dotted arrows represent other possible relations, which are not of interest to this investigation. Additionally, also interrelations within the groups of internal and external success factors are possible but are not the focus here. *Only relevant for collaboratives that include the implementation of or compliance with legislation. **Only relevant for collaboratives that include the marketing of goods or services

Apart from these criteria, we also deem positive and negative side-effects to be important aspects of the performance of a collaborative. However, they are not in the focus of the research presented here.

\subsubsection{Potential success factors for collaboratives for a more sustainable agriculture}

The reviewed literature provides a very great number and variety of conditions that can contribute to or hamper the success of collaboratives. These potential success factors can be divided into three main groups: external factors, internal factors related to characteristics of the involved actors, and internal factors related to organization and management of the collaborative itself. Each of these groups comprises a number of sub-groups of thematically related success factors (Table 1). 


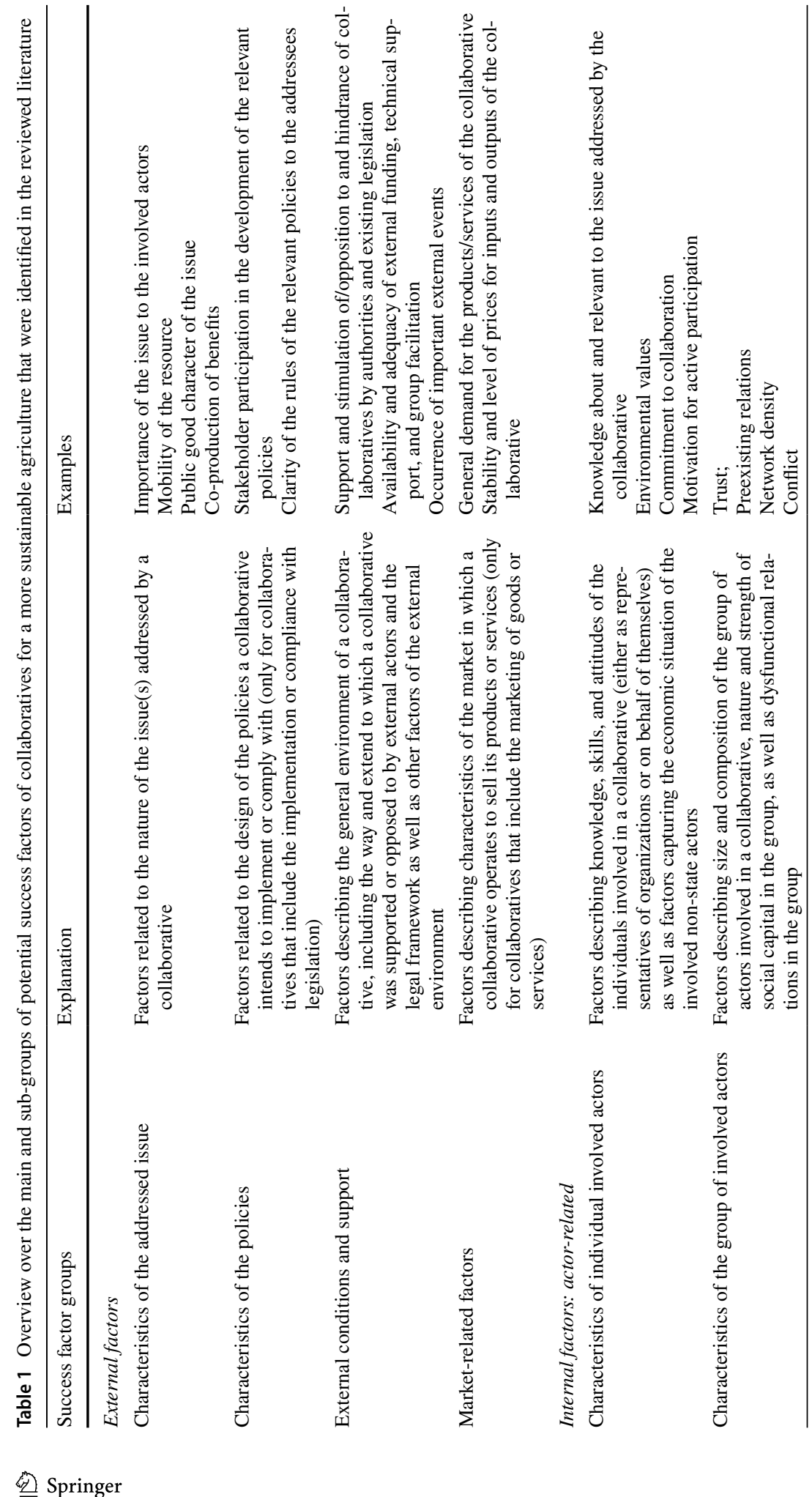




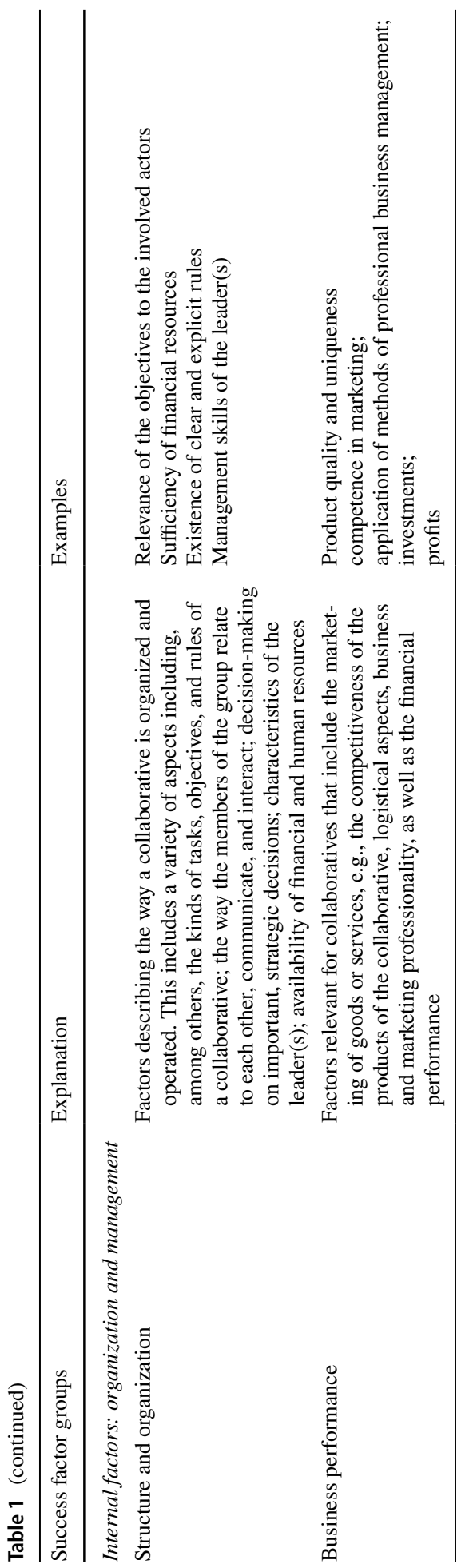




\subsection{External success factors}

The group of external success factors comprises the factors that may have an influence on the performance of a collaborative but which the collaborative can hardly influence itself. This main group includes, firstly, the specific characteristics of the issue addressed by a collaborative. For instance, smaller and stationary resources are easier to manage than large and mobile resources. These factors stem mainly from literature on collaborative common-pool resource institutions (Wade 1988; Ostrom 1990; Baland and Platteau 1996; Agrawal 2001).

Policy characteristics and market-related factors make up the second and third subgroups of external factors. Policy characteristics are relevant only for collaboratives that are concerned with the implementation of or compliance with policies. For example, a collaborative will be better able to implement or comply with a well-designed policy that matches the specific ecological, political and economic situation of the affected region as well as the capacities of the stakeholders (Cocklin et al. 2007). Likewise, market-related factors concern only collaboratives that market any goods or services. Here, moving toward sustainable agriculture and selling sustainable products will be easier for a collaborative in a favorable economic situation with, for example, stable and favorable prices (Carlberg et al. 2003; Mburu and Wale 2006), high demand (Warner 2007; Vuylsteke et al. 2008), and little competition (Carlberg et al. 2003).

The last sub-group of external factors deals with external conditions and support, i.e., factors that characterize the general environment in which a collaborative is inserted. One part of this is the political environment, for instance the extent to which governments explicitly support and actively encourage collective action (Lamprinopoulou et al. 2006; Ramdwar et al. 2013). The other aspect of this sub-group is the degree and kind of external support that a collaborative receives. Such support can take the form of financial means, technical knowledge or process facilitation and can be provided by governments or by other sources such as NGOs or private foundations.

\subsection{Internal success factors related to characteristics of the involved actors}

The internal factors can be influenced by the collaborative itself. For one, such internal factors can relate to the composition and structure of the group of involved actors. This may concern the characteristics of the individual actors involved. For instance, it is deemed more likely that a collaborative will succeed in achieving its objectives if the involved actors possess a high level of knowledge relevant to addressing the issues at hand (Newig et al. 2018) as well as pro-environmental attitudes (Lubell and Fulton 2007). On the other hand, also characteristics of the whole group of involved actors can matter, such as the size (e.g., Mills et al. 2011; Ramdwar et al. 2013; Prager 2015) and composition of the actor group (e.g., Isaac 2011, Dyer et al. 2013; Ramdwar et al. 2013), its level of social capital (e.g., Lamprinopoulou et al. 2006; Dyer et al. 2013; Prager 2015), or negative group dynamics such as conflicts (Ramdwar et al. 2013).

\subsection{Internal success factors related to organization and management of a collaborative}

The internal factors related to the way a collaborative is organized and managed relate, on the one hand, to the modus operandi of the collaborative. This includes, among other 
things, features of the objectives and rules of the collaborative, aspects of leadership, financial questions as well as the ways in which major decisions are taken.

On the other hand, the organization and management of a collaborative encompasses factors related to the way the business of a collaborative is managed. However, these factors are only relevant for collaboratives that engage in business activities. Examples for this kind of factors are the quality of the products offered by a collaborative(Carlberg et al. 2003; Azadi et al. 2010; Burandt et al. 2013), skilled marketing of the goods or services at different markets and application of methods of professional business management (Carlberg et al. 2003; Burandt et al. 2013) as well as the generation of some surplus, which allows for continued investments in the collaborative (Azadi et al. 2010) or even profits (Carlberg et al. 2003; Lamprinopoulou et al. 2006; Azadi et al. 2010).

\section{Methods}

\subsection{The case-study meta-analysis method}

The case study meta-analysis, which has also been termed case survey, is especially appropriate for the systematic integration of the insights of a larger number of qualitative case studies (Lucas 1974). The basic principle is to transform the qualitative case narratives into quantitative data and thus makes them accessible to quantitative analysis. For this transformation, a predefined coding scheme is used, which consists of a set of questions about the case studies to be answered mostly with numerical values. Thus, the case-study meta-analysis draws on a rich account of diverse case material, devised by different researchers using different research designs and brings them together under a common conceptual framework. While preserving a large amount of detail of individual case studies, the method allows for much wider generalization than single or small-N comparative case studies (Larsson 1993; Lucas 1974; Newig and Fritsch 2009).

Below, we describe each step of the performed case-study meta-analysis: (1) selection of existing case studies that are relevant to the research questions; (2) design of a coding scheme, (3) coding of the selected case studies by expert coders, (4) statistical analysis of the produced data (Larsson 1993). Online Resource 1.1 provides a more detailed account of the methodology.

\subsection{Case selection and sampling}

For this case study meta-analysis, we defined a case as an intervention (initiative, project, putting a legislation into practice, etc.) which is realized on the local or regional level (i.e., any level above farm-level and below national level), which aims at improving the sustainability of agriculture in the concerned locality or region and is carried out in any EU country in collaboration of several actors.

Thus, aside from collaboratives with ambitious objectives and the intention to realize genuine sustainable agriculture we also include collaboratives that seek incremental improvements. There are two reasons for this: first, sustainable agriculture is a very vague and ambiguous concept (Culleton et al. 1994) and has been deemed impossible to be defined in a precise and absolute way (Pretty 1995a). Therefore, it is difficult to assert whether a collaborative does in fact aim at-let alone attain-'really' sustainable agriculture. Second, Pretty (1999) argues that "everyone can take small steps, and small steps 
added together can bring about big change in the end" (p. 261). Thus, we cannot expect current initiatives to perfectly provide for sustainable agriculture. Instead, we should also value those initiatives that do not necessarily treat all sustainability dimensions equally but aim at improvements of the whole in an integrated and lasting way (Kemp et al. 2005). Hence, to be considered a relevant case for our case study meta-analysis, a collaborative may focus on only part of the sustainability dimensions (environment, economy, social) but still needs to pursue its objectives in a way that benefits or at least does not worsen the situation of the remaining, non-focal sustainability dimensions. Key selection criterion is whether there is some evidence that interventions actually aim at sustainability improvements. Cases in which such aims were obviously merely symbolic and not sincere were not included.

In searching for relevant case studies, different internet-based search strategies were used. All publications up to 2014 in English, German, or French were considered. Subsequently, all identified publications were screened with two aims: first, to accomplish the identification and matching of all publications describing the same collaborative because the unit of analysis is an intervention, not a publication (Lucas 1974); second, to check whether the described collaboratives indeed matched the definition above and were described in sufficient detail. We identified 50 relevant and usable cases (see Online Resource 1.2). Due to resource constraints and the time-intensive nature of the subsequent step of coding, only a part of these cases could be selected for further analysis. Thus, we drew a random sample of 30 cases, which were located in Germany (7), The Netherlands (5), United Kingdom (5), Italy (5), Austria (3), France (2), Belgium (2), and Czech Republic (1). The development of seven analyzed collaboratives started before 1990, thirteen collaboratives came into existence in the 1990s and the remaining ten collaboratives started out after the turn of the millennium. The earliest case started to develop in 1965 and the latest in 2010. Regarding their spatial level, two collaboratives in the sample acted on municipal or lower level, four collaboratives involved several municipalities, six collaboratives spanned one or several counties, eight collaboratives ranged over one or several subnational units (e.g., states, provinces), and ten collaboratives focused on a landscape rather than any administrative unit (see Online Resource 1.1, Table A1 for an overview over all analyzed cases).

To illustrate the kinds of analyzed collaboratives, we shortly describe three exemplary cases here: the case of the Upländer Farmer Dairy (Strauch et al.; Knickel et al. 2003; Staub 2008) began in 1986, when eight organic dairy farmers founded a cooperative in the Upland region in the state of Hesse, Germany. Initially, the cooperative sold their milk to another dairy for processing but for several reasons they opted to buy the recently closed local Upländer Dairy in 1996 and started to process and sell their milk themselves. Rates of increase in turnover and prices paid to farmers were remarkable and as of 2008, the dairy processed the milk of 130 organic dairy farmers, thus enabling and supporting their activities.

In contrast to the bottom-up initiated and purely farmer-led initiative of the Upländer Farmer Dairy, the case of the Gailtal Alp cheese (Rytkönen and Gratzer 2010; Borg and Gratzer 2013; Gratzer 2013) was initiated from the top down and included several types of actors. The case started with the foundation of the "Kärtner Agrarmarketing AG" corporation by the federal state of Carinthia, Austria in 1989. This corporation soon identified the Gailtal Alp cheese as a promising candidate for application for a Protected Denomination of Origin (PDO) at the EU. This cheese was produced with long tradition by fourteen mountain chalets in the administrative district of Hermagor. With the aim of halting the decline of farms and local dairies and protecting a traditional, extensive 
way of livestock rearing and cheese production, the state-owned corporation initiated local activity groups and networks among different interested local stakeholders. These groups, which included farmers, chalet owners, and local businesses, prepared the application for a PDO. The PDO certificate was granted in 1996. The very small scale cheese production itself is of lesser economic importance for the region. However, an annual festival initiated in 2001 related to cheese and ham from the Gailtal has had great positive effects on tourism, gastronomy and handicraft. Although the state had a very important and proactive role in the beginning of the process, it later shifted responsibilities to the stakeholders.

Different from the two previous examples, the case of the Parish Grasslands Project (Ingram et al. 2008; Peterken 2010, 2013) did not include the commercialization of specific products. In the communities of Brockweir, Hewelsfield, and St Briavels in Monmouthshire, UK, the fields of a former common had largely remained in a semi-natural state. These fields were mostly owned by smallholders or local residents who let their fields to farmers based on informal contracts. When the BSE and Food and Mouth disease crises in the end of the 1990's resulted in increased bureaucracy and restrictions, residents faced breakdown of their informal arrangements that had supported conservation of the landscape. Thus, in 2001 local residents set up a parish organization with the aims of helping residents to maintain their fields as flowery grassland and to increase interest in and knowledge of the surrounding landscape. By engaging in education (lectures, field meetings, school programs, publications), a field-by-field survey, sharing knowledge and advice, and helping field owners to enter agri-environment schemes, the intervention has created a community network of local people (residents, farmers, smallholders), who want to manage and maintain their fields for biodiversity benefits.

\subsection{Coding scheme}

The coding scheme (see Online Resource 2) contains precise and operable definitions of the key concepts to be analyzed. These are (a) the kinds and ambitiousness of the environmental, economic, and social goals of a collaborative; (b) the dependent variables (success criteria); (c) the independent variables (success factors). Included in the latter were all factors retrieved from the reviewed literature (see Sect. 2.2.2). Moreover, the coding scheme includes control variables capturing information about the available publications describing the case (e.g., involvement/neutrality of the authors) as well as information characterizing the collaborative (e.g., start year, multi-level aspects, involved actors).

Some of the identified success factors can vary significantly during the trajectory of a collaborative (e.g., trust). However, the literature provides little clarity as to the point in time at which they matter most. For this reason, these success factors were translated into two variables: one evaluates the presence of the factor at the outset of a collaborative, the other variable does the same at the latest known point in time.

Most variables in the coding scheme are questions about the case at hand and are usually answered with a numeric code. Answers are mostly expressed on a metric scale from 0 to 4, similar to a five-point Likert-scale. Additionally, the coding scheme requires for all variables a code expressing the degree of reliability of information on which the answer is based. These reliability codes range from 0 meaning 'insufficient information available' to 3 meaning 'explicit, detailed and reliable information available.' 


\subsection{Coding procedure}

After a pre-test, coding of the case studies was shared between the first author and a student assistant. The case studies were mainly coded by only one of the coders. Seven case studies were coded by both coders in order to compare coding results, discuss strong deviations, and adjust coding if needed (cf. Lucas 1974). Afterwards, both code lists were consolidated into one code list by calculating the weighted means of the codes, using the reliability values as weights. Moreover, interrater agreement was determined with an average $r_{\mathrm{wg}}$ value (James et al. 1984) of 0.86 across all variables (standard deviation 0.17). With that, interrater agreement was at an appropriate level, indicating a high degree of agreement. Additionally, for the cases coded by one coder, steps were taken to increase reliability of the codes, such as cross-check of the codes by the other coder.

\subsection{Data preparation and analysis}

The aim of our analysis was to determine which of the independent variables (representing success factors) have decisive effects on which dependent variables (representing success criteria).

We applied a stepwise exploratory approach to reduce complexity and arrive at robust and interpretable results. As a first step, we simplified and aggregated the measured constructs by means of principal component analyses (PCA) with oblique rotation (promax). We performed the PCA on conceptually related variable subsets within each of the success factor sub-groups (see Sect. 2.2.2). Where feasible, PCA integrates the variables into a smaller number of components, which represent more general constructs. Thus, PCA is able to reduce the dataset without losing much of the information provided by the original variables. All analyses were evaluated using Kaiser-Meyer-Olkin measures for sampling adequacy and Bartlett's test of sphericity, which for all analyses yielded acceptable results. All resulting constructs have acceptable reliability, with Cronbach's Alpha of at least 0.74 (for more information see Online Resource 1.3). Additionally, for the factors that can vary strongly over time, we calculated the differences between the variables evaluating these factors at the beginning of the collaboratives and at the latest known point in time. This way, additional variables representing the change of these factors over time were created.

Second, we mapped potential relations between dependent and independent variables by means of correlation analyses. We used Spearman's rank correlations to detect possible correlations. We checked all correlations for confounders by calculating partial correlations with the control variables contained in the coding scheme. This procedure provided a robust overview over covariance structures in our dataset and facilitated subsequent variable selection for regression models.

Finally, we performed multiple regression in order to assess in a broader estimation which of the selected success factors impact on which success criteria. For the regression models, all independent variables were considered that proved to have a significant and robust relation with one of the dependent variables. Due to the small sample size, models were restricted to a maximum of four variables. Therefore, we assessed different models with varying combinations of variables from at least two of the major factor groups (external, internal actor-related, internal management-related). We evaluated the regression models regarding the assumptions of normality, linearity, multicollinearity, and homoscedasticity to evaluate their generalizability. We finally selected those models with the smallest 
value of the Akaike information criterion (AIC). In order to check the robustness of our results, we additionally performed robust regression using iteratively re-weighted least squares.

\section{Results}

A list of the frequency, mean values, and standard deviations of all independent variables included in the regression models as well as success criteria ratings of the different cases are provided in Online Resource1.4. PCA proved feasible for numerous groups of related variables. Therefore, many of the variables included in the regression models are aggregates of several individual variables. Due to a high amount of missing values in the independent variables, all of our regression models are based on 19-22 cases.

The following sections present the modeling results (see Online Resource 1.5 for a detailed regression table, Online Resource 1.6 for the assessment of assumptions of the different models, and Online Resource 1.7 for the results of the robust regression). Our models contain different sets of variables. There are two reaons for that: Firstly, we restricted our models to contain a maximum of four variables and, secondly, we selected for each dependent variable the combination of independent variables that makes up the model with the smallest AIC. Figure 2 presents an overview of the regression models, showing which factors influence which success criterion.

\subsection{Factors influencing success of a collaborative in terms of the achievement of its goals}

All of the models explaining the achievement of the different kinds of goals present very high regression coefficients (adjusted R-square between 0.58 and 0.62). Thus, they cover a very large proportion of the variance of the respective success dimensions.

According to our results, for the achievement of the social goals of a collaborative the characteristics of the addressed issues and the involved actors' devotion to the collaborative at the latest known point in time are especially relevant. The characteristics of the addressed issue were summarized into a single factor of through PCA. However, they impact differently on the achievement of social goals: it is beneficial for the achievement of social goals if the addressed issues can be characterized as a public good or co-production of benefitsproblem (which is, for example, the generation of positive environmental outcomes along with increased revenues); if the benefits of the issue cannot be stored (which is the case, e.g., for clean air or the beauty of a landscape, which are typical public goods); and if the issue is of less importance to the involved actors, that is if they are not dependent on the solution of the issue. Also, the involved actors' devotion is a PCA factor containing actors' loyalty to and satisfaction with their collaborative, their motivation to participate actively, and their general environmental values and general commitment to collaborative principles. The model contains an additional variable, which is the sufficiency of overall financial resources (see Online Resource 1.5). However, this variable does not show a robust significant effect as the confidence interval of this variable contains zero. Robust regression confirmed this model with the difference that the best model obtained through robust regression contained one additional, yet non-significant variable (see Online Resource 1.6).

When it comes to the achievement of environmental goals, a collaborative is more likely to achieve these goals the more the involved actors get to trust each other toward the later 


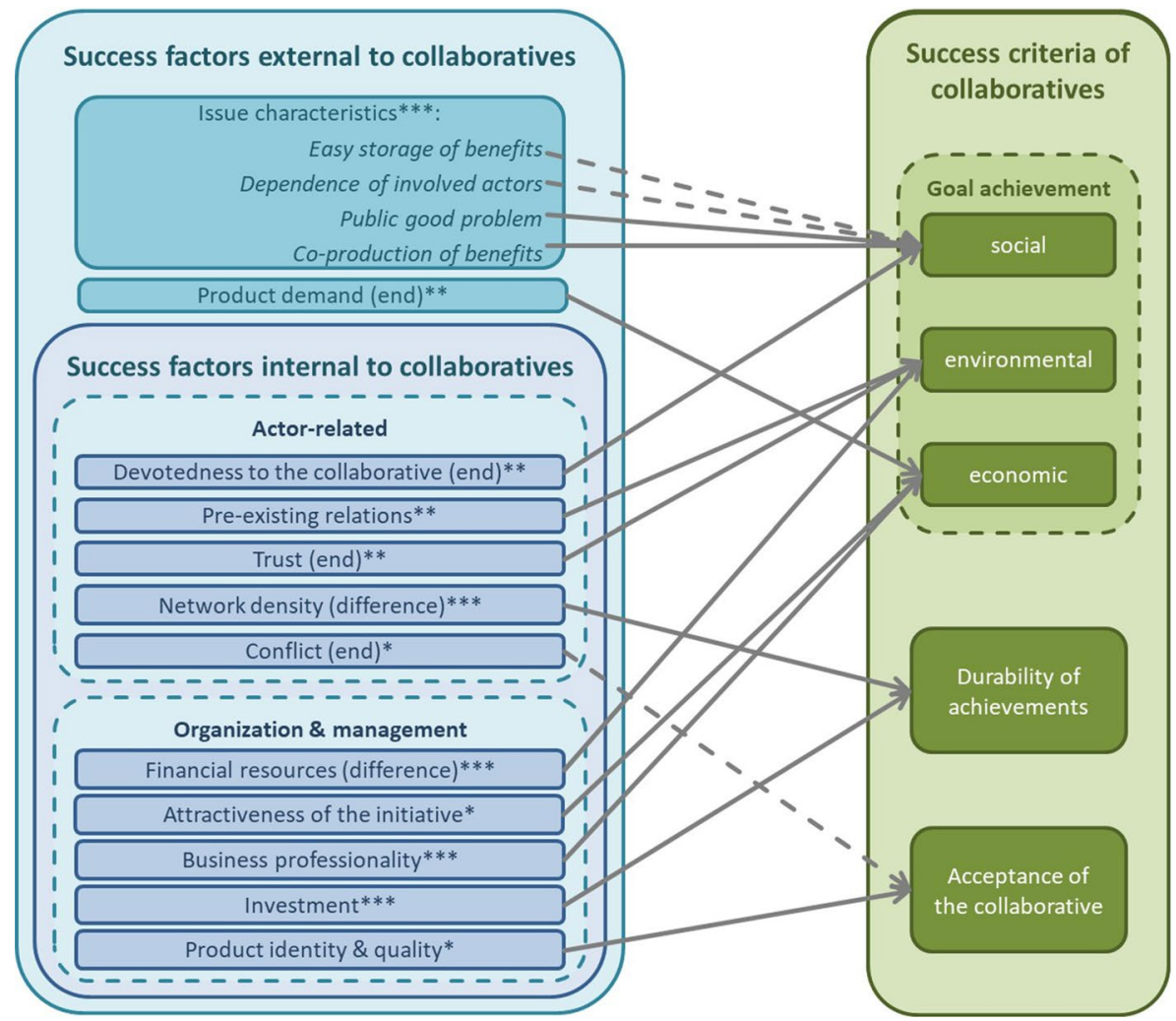

Fig. 2 Impacts of the significant success factors on the different success criteria. Continuous arrows represent positive effects, dashed arrows negative effects. The asterisks indicate the level of significance of the correlation: $* p<0.1, * * p<0.05, * * * p<0.01$. For those factors that could vary over time, the information in brackets tells at which point the factors were decisive: "end" indicates the status of the factor at the latest point in time, "difference" indicates the difference of the values of the factor between the outset of the collaborative and the latest known point in time. For the factor 'characteristics of the addressed issue,' which the PCA identified to be an overarching concept made up of several aspects, it is important to understand in which way its different aspects affect the achievement of social goals. Therefore, for this factor, the effects of its single aspects are shown

stages of the collaborative and the more the sufficiency of the overall available financial resources improves over time. Thereby, 'sufficiency' means 'having enough to carry out the tasks and functions of the collaborative'. Also relevant for the achievement of environmental goals are pre-existing relations among the actors involved in a collaborative. However, here only the minimum values of pre-existing relations showed a correlation with the achievement of environmental goals and not, for example, the average value. Therefore, what is important is a high baseline of pre-existing relations, i.e., it is favorable if all involved actors already knew each other beforehand, even if it was just to some extent. In case of the achievement of environmental goals, robust regression confirmed our results without any deviances.

The relevant factors supporting the achievement of economic goals are professional business management and the attractiveness of a collaborative to the involved actors. Also, these two factors were obtained through PCA and therefore contain several aspects. 
Professional business management comprises competence in marketing the goods or services of a collaborative at different markets and through different marketing channels, as well as the application of methods of professional business management. The attractiveness of a collaborative is increased if it pursues a narrow, focused set of goals which favor individual rather than collective goals. The creation of incentives to pursue the objectives of the collaborative and incentives to collaborate rather than to act individually further increase the attractiveness of the collaborative. An additional relevant factor for the achievement of the economic goals is a high demand for the products of a collaborative at the latest known point in time. For the achievement of the economic goals, robust regression suggested a model with three different variables as the best fitting model (existence of criteria to determine membership eligibility, continuous investments into the collaborative, and common identities of the involved actors, see Online Resource 1.7). Difference in AIC between the model suggested through normal linear regression and the model retrieved through robust regression is relatively small (41.58 and 40.95, respectively) and on conceptual grounds, the model obtained with linear regression is more meaningful. For these reasons, we decided to keep the model determined through linear regression as the best fitting model.

\subsection{Factors influencing success of a collaborative in terms of the durability of its achievements}

Also, in case of the durability of the achievements of a collaborative, the regression model accounts for a very large proportion of the variance (adjusted $\mathrm{R}$ square of 0.66 ). The model deems the following factors relevant: continued investments in the collaborative (e.g., into infrastructure, marketing campaigns, training, etc.) and a network of relations among the involved actors that increases in its density over time. The latter means that the involved actors establish more relations among each other as the collaborative develops. Also, this model contains an additional variable with $p>0.1$ whose confidence interval contains zero and whose correlation coefficient is therefore not significant (knowledge of the involved actors about the addressed issue). Robust regression confirmed these results.

\subsection{Acceptance of a collaborative}

Compared to the aforementioned regression models, the model for the acceptance of collaboratives covers a low proportion of the variance (adjusted R squared of 0.24). The model indicates that two factors are decisive in influencing the acceptance of a collaborative itself: a collaborative is better accepted if level of conflict between the involved actors is low at later stages of the collaborative. If the collaborative markets any goods or services at all, also products and services of clear and unique identity as well as high quality contribute to the acceptance of the collaborative. Robust regression confirmed our results. 


\section{Discussion}

\subsection{Discussion of the results}

First and foremost, our results show that there is no "silver bullet factor" which alone could ensure wholesale success: although we assessed in a multi-step procedure all variables of our coding scheme for their influence on the different success criteria, no single success factor proved to have a significant impact on all success criteria. Thus, for each success criterion a different set of factors is decisive. This is in line with findings and considerations in the literature we reviewed on collaborative arrangements in areas related to sustainable agriculture. Instead of one factor or a small selection of factors, also these works identify a diverse range of factors to be decisive for the performance of a collaborative (e.g., Agrawal 2001; Carlberg et al. 2003; Oerlemans and Assouline 2004; Lamprinopoulou et al. 2006; Cocklin et al. 2007; Azadi et al. 2010; Measham and Lumbasi 2013).

Perhaps the most important finding on a more general level is that more internal factors than external factors show an impact on the success of a collaborative (we identified ten internal factors and two external factors, see Fig. 2). Thus, we conclude with some caution that the performance of a collaborative is largely in the hands of the collaborative and its actors, and only to a lesser degree determined by external circumstances.

Furthermore, our results uncover a trade-off between social goals and economic achievements. For the achievement of economic goals, it is favorable if the collaborative pursues objectives that are of high relevance to the involved actors (Measham and Lumbasi 2013; Dyer et al. 2013) and contribute to the involved actors' individual self-interest rather than to collective goals (Oerlemans and Assouline 2004). In contrast, the achievement of social goals is more likely if the involved actors are little dependent on the addressed issue and therefore have weak individual interest in the issue. It strikes that this is in contrast to the literature on collaborative common-pool resource institutions, which argues that high dependence of group members on the managed resource facilitates group success (Agrawal 2001). The achievement of social goals is further supported if the collaborative addresses a public good issue (Ayer 1997), which are of collective rather than of individual interest. This finding shows that collaboratives that put a greater focus on either economic or social achievements are more likely to succeed. However, at the same time we did not find any trade-off between environmental and the other goals. Thus, while a collaborative may need to decide whether social or economic goals are of greater importance, it may be possible to achieve environmental goals along with economic and social goals.

Additionally, our results highlight the importance of success factors related to business and finances as they are central for many different success criteria: If a collaborative includes the marketing of goods or services, it is important that business and marketing are carried out in a professional way (Carlberg et al. 2003; Burandt et al. 2013). This entails assuring that the offered products or services have a unique identity (Roest and Menghi 2000; Carlberg et al. 2003; Lamprinopoulou et al. 2006) and are of good quality (Carlberg et al. 2003; Azadi et al. 2010; Burandt et al. 2013). Furthermore, availability of sufficient financial means (Azadi et al. 2010; Burandt et al. 2013) facilitates the achievement of environmental goals. Meanwhile, continued investments into the collaborative can increase the durability of the collaborative (Azadi et al. 2010). On first sight, these findings seem to be rather self-evident, especially the importance of business and finance-related factors for economic achievements. However, these findings tell an important lesson: for initiatives aiming at the improvement of the sustainability of agriculture, pure idealism is not 
sufficient. Also, classic economic criteria have to be taken into account to support a collaborative in achieving all of its goals in a durable way. Yet, as the generation of surplus profits did not prove to be a decisive factor in our analysis, the main focus regarding these financial aspects is on economic viability rather than on maximizing profitability. Thus, what matters is having enough means available for the collaborative to carry out its functions and to make continuous investments to improve its operations.

For success factors that can vary to a great extend over the trajectory of a collaborative, we assessed their status at the beginning of the collaborative, at the latest known point in time, and their change over time. Therefore, our analysis provides more detail about the point at which these factors are crucial. In case of the factor of network density of the group of involved actors (Isaac 2012), we found that what matters is its change over time. For the factors of general demand for the types of products offered by a collaborative (Carlberg et al. 2003; Mburu and Wale 2006), group members' devotedness to the collaborative (Oerlemans and Assouline 2004; Lamprinopoulou et al. 2006; Bhuyan 2007; Azadi et al. 2010), the trust (Mburu and Wale 2006; Azadi et al. 2010; Dyer et al. 2013; Prager 2015), and conflict between them (Ramdwar et al. 2013), our results show that their status at the latest known point in time matters. However, our results do not reflect cases of collaboratives that do not even take off due to, e.g., strong distrust, conflict or the absence of commitment and motivation for a cause because such cases are rarely reported. Thus, while we need to keep in mind that completely adverse initial conditions might impede a collaborative from taking off, success of a collaborative for a more sustainable agriculture seems to depend less on the conditions encountered at its outset and rather on the way it develops over time.

What is more, our results also shed some light on the conceptually ambivalent effects of the factor of network density. It has been argued that highly dense networks of relations among the involved actors facilitate collective action but provide little new information. In contrast, in less dense networks new information can become available and facilitate innovation, but this information may be difficult to diffuse through the network (Isaac 2012). Our results highlight that it is not the absolute network density but rather an increase in network density over time that matters for the durability of a collaborative and its achievements. Thus, one can say that durable collaboratives manage to consolidate their relationships over time. This finding is in line with findings from Berardo and Scholz (2010): they posit that actors in newly emerging policy arenas seek to establish relations with prominent partners in order to discover collaborative possibilities. This process creates high bridging capital in a network, which allows for efficient information exchange and is a characteristic of loose networks. However, as the policy arena matures, the advantages of bridging capital fade and bonding capital becomes more important. In this process, the number of strong ties as well as the level of reciprocity increase and allow addressing more complex cooperation problems by providing credibility.

\subsection{Methodological reflection}

Despite great care in the design and execution of the present analysis, it does present a number of challenges: while a systematic investigation of a larger number of different kinds of cases such as ours allows for insights in general patterns, it also results in a loss of information and detail. What is more, although the number of case studies that we investigated is considerably larger than in similar previous studies, it still is rather small for a study using statistical methods for data analysis. Thus, our results are mainly of explorative 
character and only offer first insights. Related to this is also the problem of missing values: Although we screened the case material to assure an appropriate level of available information on the different cases, missing values were still an issue for numerous variables. In consequence, variables with many missing values could not be considered in the statistical analysis. Thus, important influencing factors could be missing from our results.

Additionally, specific biases may pose limitations to our study. First, being based on the analysis of published material, our study is prone to a publication bias, which is the tendency to primarily report on successful cases and results with large effect sizes (cf. Cooper et al. 1997). However, our approach to evaluate the performance of the different case studies against multiple success criteria may attenuate the effect of the publication bias in two ways: first, a collaborative that is rather successful according to the success criteria applied by the authors of the original publication may perform less well if evaluated against our success criteria. Thus, using our own set of success criteria makes it more likely that our analysis includes also less successful examples of collaboratives. Second, a collaborative may perform differently with respect to the different success criteria. Therefore, the fact that we apply multiple success criteria makes it more likely that our analysis represents collaboratives with different kinds and degrees of success. A second source of bias can be the subjective numeric interpretation of qualitative information through individuals (rater bias). In face of this bias, we realized steps to align the coding decisions of the involved coders and checked for interrater agreement, which we found to be at an appropriate level (see Sect. 3.4). Still, rater bias should be noted as a possible limitation.

Last but not least, there are limits to capturing and quantifying complex social processes and phenomena such as trust and values held by actors, especially when one has to rely on second-hand information for this purpose. We addressed this challenge by taking steps to align coder decisions, controlling for biases and reliability of the information on which the coding decisions were based, and by reporting transparently on our approach.

\section{Conclusions}

In this paper, we aimed at assessing which factors influence the success of local and regional collaboratives for a more sustainable agriculture. To this end, we conducted a case study meta-analysis of 30 collaboratives from different EU countries. We considered a wide range of factors suggested to be relevant in the related literature. Our results provide insights not only on the kinds of decisive success factors and the ways they impact on the success of collaboratives (i.e., which success criteria they affect) but also regarding the stage at which certain factors play a role.

Overall, our results show that there is no silver bullet: for each success criterion (achievement of ecological, social, economic goals; durability; acceptance), a different set of factors is decisive. Consequently, there is no selection of factors that, if addressed adequately, could ensure wholesale success for a collaborative. However, while we identified a trade-off between social goals and economic benefits, we did not find a tradeoff between environmental and the other goals. What is more, we found several aspects related to finances and business management to contribute to almost all success criteria. In sum, our results show that there is no simple way to achieve overall success, but it is possible for collaboratives to pursue many different success criteria simultaneously. Importantly, our results show that collaboratives need to keep an eye on their economic viability (i.e., the ability to sustain itself financially) as it is a precondition for overall success: if a 
collaborative cannot continue due to lacking economic viability, it can no longer deliver as well in an ecological or social sense.

Furthermore, our results give reason to be optimistic about the performance of collaboratives: internal factors, i.e., the way collaboratives are composed and managed, are likely to have greater influence on the performance as uncontrollable external conditions. For our selection of cases, which all overcame an initial phase and reached some sort of maturity, conditions encountered at the outset of a collaborative seem to matter less than the way these conditions develop toward later stages. Also, the process of actors growing together, which is reflected in an increasingly dense network of relations, helps the collaborative and its achievements to persist. Therefore, rather than depending on external and predefined conditions, success rather is a result of the agency within the collaboratives. Thus, our results suggest that it is likely to be worthwhile for the initiators of a (soon to be) collaborative to invest the resources to get the collaborative started, even if initial conditions are less than optimal. However, in order to persist and be successful in the long term, collaboratives need to take care to bring actors closer together, build trust between them, keep them motivated for the cause of the collaborative, and avoid or actively resolve emerging conflicts.

Despite this positive outlook, we point out that even the most successful collaborative arrangement is never entirely perfect (Mfune 2014) and that collaboration is not a panacea. This implies that the feasibility and usefulness of establishing a collaborative have to be carefully pondered in each situation (Emerson and Nabatchi 2015).

Our results contribute to clarifying which factors are especially important for the success of collaboratives for a more sustainable agriculture. However, we also highlight that our study presents certain challenges that could be overcome in future research. To overcome the challenges related to the rather small size of our sample characterized by a great variety of collaboratives, future research could conduct an analysis similar to the one described here on a larger set of case studies or on more homogenous sets of collaboratives, e.g., just on farmer cooperatives or just on multi-stakeholder initiatives. Furthermore, with its essentially nomothetic approach our analysis tells little about the causal mechanisms through which the identified relevant factors influence the success of a collaborative. Therefore, we recommend in line with Goertz (2017) to combine the case study metaanalysis with thorough within-case inference in order to identify the causal mechanisms underlying the statistical relations found here.

Supplementary Information The online version contains supplementary material available at https://doi. org/10.1007/s10668-021-01261-y.

Acknowledgements The authors thank Edward Challies and Pim Derwort for volunteering to pre-test the coding scheme; Hanna Weber for her substantial contribution in coding the case studies; Stephanie Jahn for her expertise on the statistical analysis of the data; as well as Julia Leventon for her overall conceptual advice and input. Many thanks to five anonymous reviewers whose suggestions greatly improved earlier versions of this manuscript.

Funding Open Access funding enabled and organized by Projekt DEAL. This work received funding by the ERA NET project MULTAGRI, supported by the German Federal Ministry of Education and Research (BMBF) under grant no. 033RA01B, and by the Innovation-Incubator at Leuphana University, TM 1.4 Graduate School.

\section{Compliance with ethical standards}

Conflict of interest The authors declare that they have no conflict of interest. 
Open Access This article is licensed under a Creative Commons Attribution 4.0 International License, which permits use, sharing, adaptation, distribution and reproduction in any medium or format, as long as you give appropriate credit to the original author(s) and the source, provide a link to the Creative Commons licence, and indicate if changes were made. The images or other third party material in this article are included in the article's Creative Commons licence, unless indicated otherwise in a credit line to the material. If material is not included in the article's Creative Commons licence and your intended use is not permitted by statutory regulation or exceeds the permitted use, you will need to obtain permission directly from the copyright holder. To view a copy of this licence, visit http://creativecommons.org/licenses/by/4.0/.

\section{References}

Agrawal, A. (2001). Common property institutions and sustainable governance of resources. World Development, 29(10), 1649-1672.

Ayer, H. W. (1997). Grass roots collective action: Agricultural opportunities. Journal of Agricultural and Resource Economics, 1, 1-11.

Azadi, H., Hoseininia, G., Zarafshani, K., Heydari, A., \& Witlox, F. (2010). Factors influencing the success of animal husbandry cooperatives: A case study in Southwest Iran. Journal of Agriculture and Rural Development in the Tropics and Subtropics, 111(2), 89-99.

Baland, J. M., \& Platteau, J. P. (1996). Halting degradation of natural resources: Is there a role for rural communities? Oxford: Clarendon Press.

Berardo, R., \& Scholz, J. T. (2010). Self-organizing policy networks: Risk, partner selection, and cooperation in estuaries. American Journal of Political Science, 54(3), 632-649.

Beus, C. E., \& Dunlap, R. E. (1990). Conventional versus alternative agriculture: The paradigmatic roots of the debate. Rural Sociology, 55, 590-616.

Bhuyan, S. (2007). The "people" factor in cooperatives: an analysis of members' attitudes and behavior. Canadian Journal of Agricultural Economics, 55(3), 275-298.

Borg, E. A., \& Gratzer, K. (2013). Collective brand strategy, entrepreneurship, and regional growth: The role of a protected designation of origin (PDO). Journal of World Economic Research, 2(3), 26-38.

Burandt, A., Lang, F., Schrader, R., \& Thiem, A. (2013). Working in regional agro-food networks: Strengthening rural development through cooperation. Eastern European Countryside, 19(1), $153-176$.

Carlberg, J. G., Holcomb, R. B., \& Ward, C. E. (2003). Success factors for value-added new generation cooperatives: Selected paper prepared for presentation at the Southern Agricultural Economics Association Annual Meeting, Mobile, Alabama, February 1-5, 2003. http://ageconsearch.umn.edu/ bitstream/35095/1/sp03ca02.pdf.

Clark, J. (2006). The institutional limits to multifunctional agriculture: subnational governance and regional systems of innovation. Environment and Planning C: Government and Policy, 24(3), 331-349.

Cobb, D., Dolman, P., \& O'Riordan, T. (1999). Interpretations of sustainable agriculture in the UK. Progress in Human Geography, 23(2), 209-235.

Cocklin, C., Mautner, N., \& Dibden, J. (2007). Public policy, private landholders: perspectives on policy mechanisms for sustainable land management. Journal of Environmental Management, 85(4), 986-998.

Concepción, E. D., Díaz, M., \& Baquero, R. A. (2008). Effects of landscape complexity on the ecological effectiveness of agri-environment schemes. Landscape Ecology, 23(2), 135-148.

Cooper, H. M., DeNeve, K., \& Charlton, K. (1997). Finding the missing science: The fate of studies submitted for review by a human subjects committee. Psychological Methods, 2(4), 447-452.

Culleton, N., Tunney, H., \& Coulter, B. (1994). Sustainability in Irish agriculture. Irish Geography, 27(1), 36-47.

de Roest, K., \& Menghi, A. (2000). Reconsidering 'traditional' food: The case of Parmigiano Reggiano Cheese. SociologiaRuralis, 40(4), 439-451.

Donald, P. F., \& Evans, A. D. (2006). Habitat connectivity and matrix restoration: the wider implications of agri-environment schemes. Journal of Applied Ecology, 43(2), 209-218.

Dyer, J. C., Leventon, J., Stringer, L. C., Dougill, A. J., Syampungani, S., Nshimbi, M., et al. (2013). Partnership models for climate compatible development: experiences from Zambia. Resources, 2, 1-25.

Emerson, K., \& Nabatchi, T. (Eds.). (2015). Collaborative governance regimes. Washington: Georgetown University Press. 
Fischer, A. P., Klooster, A., \& Cirhigiri, L. (2018). Cross-boundary cooperation for landscape management: Collective action and social exchange among individual private forest landowners. Landscape and Urban Planning, 188, 151-162.

Gibson, C., Williams, J., \& Ostrom, E. (1999). Social capital and the governance of forest resources. Workshop in political theory and policy analysis.

Goertz, G. (2017). Multimethod research, causal mechanisms, and case studies: An integrated approach (6th ed.). Princeton: Princeton University Press.

Gratzer, K. (2013). GailtalerAlmkäse: Regional development through protected denomination of origin. In P. Rytkönen, G. Hernandez, L. Arturo, \& U. Jonsson (Eds.), From local champions to global players: Essays on the history of the dairy sector. Stockholm studies in economic history (Vol. 61, pp. 171-192). Stockholm: ActaUniversitatisStockholmiensis.

Horlings, I. (1994). Policy conditions for sustainable agriculture in the Netherlands. The Environmentalist, $14(3), 193-199$.

Hubeau, M., Marchand, F., \& van Huylenbroeck, G. (2017). Sustainability experiments in the agri-food system: Uncovering the factors of new governance and collaboration success. Sustainability, 9(6), 1027.

Ingram, J., Mills, J., Short, C., Reed, M., Gibbon, D., Dwyer, J., et al. (2008). Evaluation of key factors that lead to successful agri-environmental co-operative schemes: A literature review of behavioural change mechanisms in agriculture (Vol. II).

Isaac, M. E. (2012). Agricultural information exchange and organizational ties: The effect of network topology on managing agrodiversity. Agricultural Systems, 109, 9-15.

James, L. R., Demaree, R. G., \& Wolf, G. (1984). Estimating within-group interrater reliability with and without response bias. Journal of Applied Psychology, 69, 85-98.

Kemp, R., Parto, S., \& Gibson, R. W. (2005). Governance for sustainable development: Moving from theory to practice. International Journal of Sustainable Development, 8(1/2), 12-30.

Knickel, K., Schaer, B., \& Sprenger, B. (2003). Macro-level analysis of food supply chain dynamics and diversity: An overview for Germany.

Lamichhane, J. R., Aubertot, J.-N., Begg, G., Birch, A. N. E., Boonekamp, P., Dachbrodt-Saaydeh, S., et al. (2016). Networking of integrated pest management: A powerful approach to address common challenges in agriculture. Crop Protection, 89, 139-151.

Lamprinopoulou, C., Tregear, A., \& Ness, M. (2006). Agrifood SMEs in Greece: The role of collective action. British Food Journal, 108(8), 663-676.

Larsson, R. (1993). Case survey methodology: Quantitative analysis of patterns across case studies. The Academy of Management Journal, 36(6), 1515-1546.

Leventon, J., Schaal, T., Velten, S., Dänhardt, J., Fischer, J., Abson, D. J., et al. (2017). Collaboration or fragmentation? Biodiversity management through the common agricultural policy. Land Use Policy, 64, 1-12.

Lubell, M., \& Fulton, A. (2007). Local policy networks and agricultural watershed management. Journal of Public Administration Research and Theory, 18(4), 673-696.

Lucas, W. A. (1974). The case survey method: Aggregating case experience. Santa Monica, CA.

Margerum, R. D. (2011). Beyond consensus: Improving collaborative planning and management. Cambridge, MA: MIT Press.

Markelova, H., \& Mwangi, E. (2010). Collective action for smallholder market access: Evidence and implications for Africa. Review of Policy Research, 27(5), 621-640.

Mburu, J., \& Wale, E. (2006). Local organizations involved in the conservation of crop genetic resources: Conditions for their emergence and success in Ethiopia and Kenya. Genetic Resources and Crop Evolution, 53(3), 613-629.

Measham, T. G., \& Lumbasi, J. A. (2013). Success factors for community-based natural resource management (CBNRM): Lessons from Kenya and Australia. Environmental Management, 52(3), 649-659.

Mfune, O. (2014). Managing common pool resources without state support: Insights from Shisholeka community in Central Zambia. Environment, Development and Sustainability, 16(6), 1263-1280.

Mills, J., Gibbon, D., Ingram, J., Reed, M., Short, C., \& Dwyer, J. (2011). Organising collective action for effective environmental management and social learning in Wales. The Journal of Agricultural Education and Extension, 17(1), 69-83.

Moschitz, H., Tisenkopfs, T., Brunori, G., Home, R., Kunda, I., \& Šūmane, S. (2014). Final report of the SOLINSA project: Deliverable No. 8.2.

Newig, J., Challies, E., Jager, N. W., Kochskämper, E., \& Adzersen, A. (2018). The environmental performance of participatory and collaborative governance: A framework of causal mechanisms. Policy Studies Journal, 34(4), 217.

Newig, J., \& Fritsch, O. (2009). Environmental governance: participatory, multi-level-and effective? Environmental Policy and Governance, 19, 197-214. 
Newig, J., Jager, N. W., Kochskämper, E., \& Challies, E. (2019). Learning in participatory environmental governance: Its antecedents and effects. Findings from a case survey meta-analysis. Journal of Environmental Policy and Planning, 64(3), 213-227.

Newman, L., \& Dale, A. (2007). Homophily and agency: Creating effective sustainable development networks. Environment, Development and Sustainability, 9(1), 79-90.

Oerlemans, N., \& Assouline, G. (2004). Enhancing farmers' networking strategies for sustainable development. Journal of Cleaner Production, 12(5), 469-478.

Ostrom, E. (1990). Governing the Commons: The evolution of institutions for collective action. Cambridge: Cambridge University Press.

Peterken, G. (2010). Community grassland conservation on a former common in the Wye Valley. Landscape Archaeology and Ecology, 8, 168-171.

Peterken, G. (2013). Community grassland conservation on a former common in the Wye Valley, England. In I. D. Rotherham (Ed.), Cultural severance and the environment: The ending of traditional and customary practice on commons and landscapes managed in common, environmental history (Vol. 2, pp. 413-418). New York: Springer.

Prager, K. (2015). Agri-environmental collaboratives for landscape management in Europe. Current Opinion in Environmental Sustainability, 12, 59-66.

Prager, K., Hagemann, N., Schuler, J., \& Heyn, N. (2011). Incentives and enforcement: The institutional design and policy mix for soil conservation in Brandenburg (Germany). Land Degradation and Development, 22(1), 111-123.

Pretty, J. N. (1995a). Participatory learning for sustainable agriculture. World Development, 23(8), 1247-1263.

Pretty, J. N. (1995b). Regenerating agriculture: policies and practice, for sustainability and self-reliance. London: Earthscan Publications, National Academy Press.

Pretty, J. N. (1999). Can sustainable agriculture feed Africa? New evidence on progress, processes and impacts. Environment, Development and Sustainability, 1(3/4), 253-274.

Ramdwar, M. N. A., Ganpat, W. G., \& Bridgemohan, P. (2013). Exploring the barriers and opportunities to the development of farmers' groups in selected Caribbean countries. International Journal of Rural Management, 9(2), 135-149.

Rytkönen, P., \& Gratzer, K. (2010). When do trademarks create new markets? Entrepreneurship, brands and growth-experiences from small scale cheese production in Austria, Spain and Sweden. In I. Darnhofer \& M. Grötzer (Eds.), Building sustainable rural futures: The added value of systems approaches in times of change and uncertainty (pp. 1661-1670). San Francisco: BOKU.

Sabatier, P. A. (1988). An advocacy coalition framework of policy change and the role of policy-oriented learning therein. Policy Sciences, 21(2-3), 129-168.

Schlager, E. (1995). Policy making and collective action: Defining coalitions within the advocacy coalition framework. Policy Sciences, 28(3), 243-270.

Schoon, M., \& Cox, M. (2018). Collaboration, adaptation, and scaling: Perspectives on environmental governance for sustainability. Sustainability, 10(3), 679.

Shaw, L., Lubell, M., \& Ohmart, C. (2009). The evolution of local partnerships for sustainable agriculture. In Annual meeting of the American Political Science Association. Toronto.

Shiferaw, B., Hellin, J., \& Muricho, G. (2011). Improving market access and agricultural productivity growth in Africa: What role for producer organizations and collective action institutions? Food Security, 3(4), 475-489.

Staub, M. (2008). FAIRTRADE in der BIO-KNOSPE: Strategische Optionen zur Erfüllung einer Konsumentinnen- und Produzenten-Erwartung. Therwil.

Strauch, C., Schaer, B., Peter, S., Gountaras, K., \& Knickel, K. Marketing Sustainable Agriculture: An analysis of the potential role of new food supply chains in sustainable rural development: Upländer Dairy. Case Study Report. SUS-CHAIN, QLK5-CT-2002-01349.

Uetake, T. (2014). Agri-environmental management through collective action. EuroChoices, 13(3), $29-34$.

Velten, S., Leventon, J., Jager, N. W., \& Newig, J. (2015). What is sustainable agriculture? A systematic review. Sustainability, 7(6), 7833-7865.

Velten S (2014) When are collaborative interventions for a more sustainable agriculture successful? Towards an analytical framework. The 4th World Sustainability Forum 2014. https://doi.org/10.3390/ wsf-4-g004. https://www.sciforum.net/paper/view/conference/2466.

Vuylsteke, A., Simoncini, A., \& van Huylenbroeck, G. (2008). Farmers' search for sustainable chain alliances to market quality food products. In B. Dedieu \& S. Zasser-Bedoya (Eds.), Empowerment of the rural actors: A renewal of Farming Systems perspectives (pp. 267-276). INRA SAD: Thiverval-Grignon. 
Wade, R. (1988). Village republics: Economic conditions for collective action in South India. Oakland: ICS Press.

Warner, K. D. (2007). The quality of sustainability: Agroecological partnerships and the geographic branding of California winegrapes. Journal of Rural Studies, 23(2), 142-155.

Publisher's Note Springer Nature remains neutral with regard to jurisdictional claims in published maps and institutional affiliations. 